\title{
TEM LUGAR PARA AS BICHAS? - DISCURSO ACERCA DAS SEXUALIDADES DISSIDENTES E PRÁTICAS HETEROTÓPICAS
}

\author{
HAVE PLACE FOR FAGGOTS? - SPEECH ABOUT DISSIDENT \\ SEXUALITIES AND HETEROTOPIC PRACTICES
}

\begin{abstract}
Samilo Takara ${ }^{1}$
Vinícius Colussi Bastos ${ }^{2}$

\section{RESUMO}

Este texto tem como questão orientadora problematizar: de que maneira as experiências de corpos e vidas dissidentes das normas de gênero e sexualidade nas lógicas produtivas e coercitivas do poder, que naturaliza a heterossexualidade, são inscritas de modos diferentes nas localizações Interior e Capital? Desse modo, o objetivo geral deste estudo é problematizar as relações entre espaço, sexualidades e dissidências das normas de gênero e sexualidade que as bichas provocam. O texto é embasado pelos referenciais teóricos dos estudos culturais e estudos queer e inscreve-se sob métodos bibliográfico e documental em um estudo que é qualitativo e exploratório na análise do vídeo "Gay do interior X gay da capital: beijo, namoro, aplicativo..." do youtuber Klébio Damas. Considera-se que corpos e vidas dissidentes das normas são capturados nas relações de poder e no diálogo com as representações apresentadas, compreende-se que os processos de experiência que perpassam as sexualidades dissidentes são vividos pelas bichas de forma heterotópica nesses espaços.
\end{abstract}

Palavras-chaves: Sexualidades. Bichas. Localização. Heterotopias.

\section{ABSTRACT}

This text has as a guiding question to problematize: how are the experiences of bodies and lives dissenting from the norms of gender and sexuality in the productive and coercive logics of power, which naturalizes heterosexuality, are inscribed in different ways in the Interior and Capital locations? Thus, the general objective of this study is to problematize the relationships between space, sexualities and dissidences of the norms of gender and sexuality that fagots provoke. The text is based on the theoretical references of cultural studies and queer studies and is inscribed under bibliographic and documentary methods in a study that is qualitative and exploratory in the analysis of the video "Gay from the countryside vs. gay from the capital: kiss, dating, application .. . "By youtuber Klébio Damas. It is

\footnotetext{
${ }^{1}$ Atualmente é Professor do Departamento de Educação e da Especialização em Gênero e Diversidade na Escola do Campus Rolim de Moura da Fundação Universidade Federal de Rondônia (UNIR). Pós-Doutor em Comunicação (Universidade Estadual de Londrina-PR). Doutor e mestre em Educação (Universidade Estadual de Maringá-PR).e-mail: samilo@unir.br

${ }^{2}$ Atualmente é professor Assistente no Departamento de Biologia Geral - UEL. Doutor em Ensino de Ciências e Educação Matemática, pelo Programa de Pós-graduação em Ensino de Ciências e Educação Matemática (PECEM) da Universidade Estadual de Londrina - UEL. e-mail: colussi.bastos@gmail.com
} 
considered that bodies and lives dissenting from the norms are captured in power relations and in the dialogue with the presented representations, it is understood that the processes of experience that permeate dissident sexualities are lived by the fagots in a heterotopic way in these spaces.

Keywords: Sexualitie.; Faggots. Location. Heterotopias.

\section{INTRODUÇÃO}

Este texto é uma proposta de diálogo por meio de contribuições teóricas e análises com o Dossiê Dissidências de gênero e sexualidade(s) em contextos interioranos e/ou rurais: cruzando temas, problemas e perspectivas contemporâneas. Acompanhando a chamada que propõe a discussão de "múltiplas formas de viver a identidade de gênero, a identidade sexual e/ou práticas sexuais dissidentes à heterossexualidade compulsória e dialogar sobre as negociações de enfrentamento e resistência à adequação encenadas em contextos fora dos grandes centros urbanos"3.

Ao lermos esta chamada, uma questão orientadora se fez ao processo de problematizar essas experiências dissidentes que incitou o incômodo na produção desta análise: as experiências de corpos e vidas dissidentes das normas de gênero e sexualidade nas lógicas produtivas e coercitivas do poder que naturaliza a heterossexualidade são inscritas de modos diferentes nas localizações Interior e Capital? Desse modo, o objetivo geral deste estudo é problematizar as relações entre espaço, sexualidades e dissidências das normas de gênero e sexualidade a partir das bichas.

Para tanto, os objetivos específicos que produzem essa pesquisa foram: apresentar o contexto científico-político que orienta este estudo; discutir relações entre espaço e sexualidade; problematizar condições de vidas e corpos dissidentes em diálogo com o vídeo "Gay do interior X gay da capital: beijo, namoro, aplicativo...” do youtuber Klébio Damas postado em seu canal no YouTube "Mundo Paralelo".

No intuito de contribuir com a discussão possível entre a narrativa midiática que ilustra e, ao mesmo tempo, denota as inscrições sobre a lógica Capital e Interior e suas disparidades e

\footnotetext{
${ }^{3}$ Trecho inscrito na Chamada para o Dossiê apresentado no site da revista Debates Insubmissos. Disponível em: https://drive.google.com/file/d/1-54Lc3IC8JKuRKBsk0ltuN9XBnRdR34W/view. Acesso em: 04 mai. 2020.
} 


\section{novistet

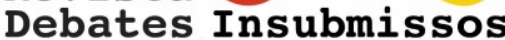

semelhanças entre as vidas e os corpos dissidentes da heterossexualidade naturalizada. Assim, o texto é construído em diálogo com os termos corpos e vidas dissidentes, para provocar uma ideia de similaridade entre as experiências de Lésbicas, Gays, Bissexuais, Travestis, Transexuais, Intersexo, Assexuais e outras possibilidades de vivenciar as relações de gênero e sexualidade ( $\operatorname{LGBTIA}+{ }^{4}$ ), no que diz respeito aos modos pelos quais o sistema heterocentrado marginaliza essas outras vivências.

Ao mesmo tempo, é necessário registrar especificidades das experiências de cada um dos grupos citados pela sigla que tenta homogeneizar causas tão singulares que são, por vezes, invisibilizadas em relação a outras experiências possíveis. Reconhecer essas diferenças é uma das condições produtivas do processo político e científico que os estudos de gênero e sexualidades precisam problematizar para não entrarmos na ideia homogeneizadora que os movimentos sociais por vezes são localizados pela mídia, pela publicidade e pela sociedade para encontrar um comum em detrimento de vidas outras.

Entre as vivências marginalizadas, encontramos a bicha como uma figura pedagógica, cultural e monstruosa. O limite entre a ideia de masculinidade e feminilidade que produz outras experiências diante da dimensão das sexualidades e das identidades de gênero. Provocar a discussão questionando o lugar em que a bicha pode estar é uma forma de reconhecer que a dicotomia interior/capital não exime as marcações do machismo, da homofobia e da misoginia que precisam ser problematizadas e que são instabilizadas pela presença da bicha como figura cultural e política que desconforta o ideal da homossexualidade (TAKARA, 2017).

No sentido de articular este estudo numa dimensão política e acadêmica, o texto inicia apresentando as posições teóricas e provisórias que se sustentam por inscrições discutidas. Embasamo-nos nos estudos culturais e nos estudos queer para discutir as dimensões da cultura,

\footnotetext{
${ }^{4}$ A sigla LGBTIA+ refere-se ao movimento político e representativo de Lésbicas, Gays, Bissexuais, Travesti, Transexuais, Intersexos, Assexuais e as outras formas de viver e ser que são possibilidades na dimensão das identidades sexuais e de gênero. Entretanto, a sigla é móvel e passou por diversas alterações no decorrer da história do movimento e reapresenta os grupos que problematizam formas de afeto e sexualidades não referenciadas pela cis-heteronorma. Compreende-se o uso do Q de queer como uma possibilidade que se apresenta em variações da sigla, mas por compreender queer a dimensão teórico-política de desidentificação com categorias e a problematização das identidades, o queer é pensado neste texto como teoria e não como identificação específica de grupo como as letras mencionadas no decorrer do texto.
} 


\section{Revista \\ Debates Insubmissos}

as possibilidades de instabilidade sobre as discussões de gênero e sexualidade e a necessidade de provocar e assumir a provisoriedade e as condições instáveis da contemporaneidade para pensar as relações entre sexualidades e culturas nos espaços sociais.

Em seguida, o texto problematiza a caracterização dos espaços e o conceito de heterotopia trabalhado por Michel Foucault $(2006,2013)$ para analisar as dimensões espaciais e as necessidades culturais, políticas, éticas e estéticas que inscrevem as experiências de corpos e vidas dissidentes na lógica dos espaços. Para contribuir na discussão, o texto problematiza que a espacialidade dessas pessoas é uma exigência/necessidade heterotópica. Assim, inicia-se, neste instante do texto a necessidade de problematizarmos se existem espaços possíveis para essas que são compreendidas dissidências do sistema heterossexual.

Após essas localizações teóricas e políticas, o texto apresenta o tópico Métodos e outras posições no intuito de especificar neste estudo as demandas científicas e específicas das Ciências Humanas e inscrever esta pesquisa em uma proposta qualitativa, exploratória e que faz usos dos métodos bibliográfico e documental no intuito de apresentar conceitos e elementos teóricos, discutir a relação possível entre esses conceitos e os discursos acerca da localização Interior e Capital para a problematização da questão orientadora.

O próximo tópico abordado neste texto é Interior e/ou Capital: existe lugar para as bichas? em que problematizamos a relação dos discursos com as possibilidades de experiências e vivências de corpos e vidas dissidentes das normas de gênero e sexualidades para gerar outras possibilidades de analisar e problematizar as dimensões divergentes que inscrevem sentidos acerca dos espaços possíveis para estas pessoas. Desse modo, iniciamos um diálogo entre os discursos apresentados pelo youtuber Klébio Damas sobre a oposição Capital e Interior e discutir as possíveis analíticas que inscrevem este discurso na malha de poder que estamos inseridos.

Ao fim deste texto apresentamos as Considerações Finais no intuito de retomar a pesquisa, apresentar a questão orientadora, os objetivos, as referências teóricas, os métodos e os argumentos para registrar que existem disparidades entre Interior e Capital, entretanto, os corpos e as vidas que escapam também estão inscritas nas redes e relações de poder e, desse 
modo, o texto propõe continuidade de discussões no sentido de desarmar a heterossexualidade naturalizada.

\section{POSIÇÕES TEÓRICAS E OUTRAS PROVISORIEDADES}

Para pensar a dinâmica acerca das espacialidades e localidades que orientam a leitura deste estudo, é necessário iniciar pelo referencial teórico que estrutura esta pesquisa. Esta escolha é uma forma de indicar quais as perspectivas que são possíveis como elementos de leitura da analítica empreendida nesta problematização. Desse modo, instigados pelos estudos culturais, compreendemos que "[...] o terreno de sua investigação circunscreva-se aos temas vinculados às culturas populares e aos meios de comunicação de massa e, posteriormente, a temáticas relacionadas com as identidades, sejam elas sexuais, de classe, étnicas, geracionais etc." (ESCOSTEGUY, 2010, p. 35).

Assim, acompanhamos a leitura de Nelson, Treichler e Grossberg (2008) em que os estudos culturais se identificam como um trabalho teórico e político. Desse modo, as perspectivas que orientam esta pesquisa estão vinculadas a uma posição de análise e de perspectiva intelectual que não se desassociam das práticas políticas e das relações entre os sujeitos nos espaços sociais.

[...] os Estudos Culturais são tanto uma tradição intelectual quanto política. Existe uma espécie de dupla articulação da cultura nos Estudos Culturais, onde "cultura" é simultaneamente o terreno sobre o qual a análise se dá, o objeto de estudo e o local da crítica e intervenção política. Mas os Estudos Culturais não abraçam todas as posições políticas. (JOHNSON apud NELSON; TREICHLER; GROSSBERG, 2008, p. 15)

Desse modo, compreender as localizações das identidades culturais de indivíduos que vivem e realizam suas sexualidades de forma dissidente aos padrões sociais e culturais que localizam a cisgeneridade a heterossexualidade como padrões naturais, é uma tarefa de problematização: “[...] de formações históricas específicas, de histórias e repertórios culturais de enunciação muito específicos, que ela pode constituir um 'posicionamento', ao qual nós podemos chamar provisoriamente de identidade" (HALL, 2003, p. 409).

Além desses elementos, reconhecemos nos estudos culturais uma indicação de outras "[...] formas de ver, ler, escrever e entrar em contato com outro universo cultural". Existe uma 
possibilidade neste referencial teórico em analisar os sentidos e as significações das mídias e os modos como esses discursos produzem modos de ser e de agir no mundo (TERUYA, 2009, p. 156)

Assim, alinhadas as potencialidades dos estudos culturais, acompanhamos a análise da ideia de diáspora desenvolvida por Stuart Hall (2003, p. 391) ao contar sobre sua condição diante das culturas jamaicana e inglesa. $\mathrm{O}$ autor mostra que não era uma escolha os modos como era lido nos espaços e nos discursos que produziam a ideia das identidades jamaicana e inglesa, tendo em vista que os primeiros o viam como inglês e os últimos diziam que por sua ascendência, Hall (2003) era jamaicano.

Conheço intimamente os dois lugares, mas não pertenço completamente a nenhum deles. E esta é exatamente a experiência diaspórica, longe o suficiente para experimentar o sentimento de exílio e perda, perto o suficiente para entender o enigma de uma "chegada" sempre adiada (HALL, 2003, p. 393).

Alinhavamos as contribuições deste referencial teórico as provocações dos estudos queer que “[...] busca tornar visíveis as injustiças e violências implicadas na disseminação e da demanda do cumprimento das normas e das convenções culturais, violências e injustiças envolvidas tanto na criação dos 'normais' quanto dos 'anormais' (MISKOLCI, 2012, p. 26). Com isso, pensar gênero e sexualidade em relação aos campos dos estudos culturais e da teoria queer é compreender os incômodos da identidade cultural, seu caráter provisório, bem como as localizações que inserem as vidas e os corpos em uma dimensão do sistema sexo/gênero e geram, então, “[...] máquinas, produtos, instrumentos, aparelhos, truques, próteses, redes, aplicações, programas, conexões, fluxos de energia e de informação, interrupções e interruptores, chaves, equipamentos, formatos, acidentes, detritos, mecanismos, usos, desvios..." (PRECIADO, 2019, p. 412).

Em outro sentido, a articulação entre estudos culturais e teoria queer visa problematizar as localizações teórico-políticas que incidem sobre vidas e corpos e organizam modos específicos que definem as noções de identidade e diferença. Desse modo, compreender as culturas, as dinâmicas políticas e as produções de corpos e subjetividades na lógica de uma sociedade que normaliza a heterossexualidade às custas das sexualidades denominadas por desviantes ou dissidentes. 


\section{neyste

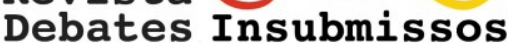

Ser queer significa levar um outro tipo de vida. Não é sobre o mainstream, margens de lucro, patriotismo, patriarcado ou sobre ser assimilado. Não é sobre diretores executivos, privilégio e elitismo. É sobre estar nas margens, definindo nós mesmas; é sobre desfazer gênero e segredos, sobre o que está abaixo do sinto e, profundo, dentro do coração. É sobre a noite. Ser queer é ser "local" porque sabemos que cada uma de nós, cada corpo, cada gozo, cada coração e cu e pau é um mundo de prazeres esperando para serem explorados. Cada uma de nós é um mundo de possibilidades infinitas (MANIFESTO QUEER NATION, 2016, p. 3).

Assim, acompanhamos as contribuições de Butler (2018) e Preciado (2019) para compreender como esses sistemas sexo/gênero produzem interpretações identitárias, localizações e, ao mesmo tempo, deslocamentos embasados na ideia de que a identidade seria uma categoria fixa que é diretamente relacionada a diferença. Em contraste, seguimos por outra direção, assim, “[...] o gênero não é de modo algum uma identidade estável nem lócus de agência do qual procederiam diferentes atos; ele é, pelo contrário, uma identidade constituída de forma tênue no tempo" (BUTLER, 2018, p. 3).

É relevante retomar, como nos explica Miskolci (2012, p. 24) e o Manifesto Queer Nation (2016) que queer "é um xingamento, é um palavrão em inglês" (MISKOLCI, 2012, p. 24). Assim, usar o termo é uma estratégia para lembrarmos “[...] como somos percebidas pelo resto do mundo. [...] Usamos queer como homens que amam lésbicas e lésbicas que amam ser queer. Queer ao contrário de gay, não significa macho” (MANIFESTO QUEER NATION, 2016, p. 9).

Aproximados da teoria queer, pensamos com a figura da bicha por sua potência transgressora ao sistema heteronormativo e brasilidade. Como apresentado por Takara (2017):

A bicha não tem a ilusão de que há algo para ensinar, aprender ou acreditar que seja redentor das formas de educar ou em uma forma específica de tornar-se sujeito. Vivida, ela percebeu que essa pretensão é ineficaz. E, se há o que interessa à bicha é o potencial de inventar outras formas de constituir-se como sujeito e de empreender outras possibilidades de existir (TAKARA, 2017, p. 153).

Diante disso, existem olhares que são construídos para pensar e sentir de outros modos. A relação entre cultura, discurso, linguagem e corpo estão alinhavadas a ideia de localidade, as noções de espaço e de território para problematizarmos as possibilidades de ser e de agir no mundo. Desse modo, o texto aqui apresentado segue uma política e uma prática desestabilizadora das ideias de identidade e de cultura produzindo também os aspectos que são inscritos nos corpos e as vidas de pessoas LGBTIA+. 
Eles nos ensinaram que queer bem comportada não sente raiva. Nos ensinaram tão bem, que não apenas escondemos a nossa raiva deles, como também de nós mesmas. Escondemos até de nós mesmas. Escondemos com abuso de drogas, suicídio ou na busca exagerada por nos superarmos na esperança de que possamos provar pra eles que valemos alguma coisa. Eles nos atacam, nos esfaqueiam, nos alvejam, nos bombardeiam em números cada vez mais altos e ainda nos preocupamos quando um punhado de queers com raiva, empunham cartazes e sinais dizendo "caiam fora!". [...] Permita-se sentir raiva. Permita-se sentir raiva pois o preço da visibilidade é a constante ameaça de violência, violência homofóbica com a qual praticamente cada setor dessa sociedade contribui. Permita-se sentir raiva do fato de que não há lugar neste país onde estejamos seguras, nenhum lugar onde não somos alvo do ódio e do ataque, do nosso próprio desprezo, do suicídio - do armário (MANIFESTO QUEER NATION, 2016, p. 11).

Desse modo, estimulados pela contribuição da raiva e dos sentimentos que nos perpassam, bem como nossas localizações corporais, éticas e estéticas, também estamos localizando nossos posicionamentos, que, com base em Haraway (1995, p. 27) “[...] implica em responsabilidade por nossas práticas capacitadoras. Em consequência, a política e a ética são a base das lutas pela contestação a respeito do que pode ter vigência como conhecimento racional". Assim, uma perspectiva contrassexual é um modo de perceber que desenvolver uma crítica que desnaturalize a sexualidade e reconheça o processo de historicidade das tecnologias que mostram que a ideia de natureza é "[...] um efeito de negociação permanente das fronteiras entre humano e animal, corpo e máquina, mas também entre órgão e plástico" (PRECIADO, 2019, p. 412).

Embasados por essas perspectivas, o objetivo de problematizar a localização das sexualidades desviantes ou dissidentes e as estratégias de vida é uma das formas de problematizar os conhecimentos acerca das experiências de centro e de margem que indicam os sentidos e as práticas de pessoas não heterossexuais, em especial as bichas, nos sistemas culturais que vivemos. Assim, essas reflexões teóricas localizam as possibilidades de pensar a experiência não heterossexual e questionar, no diálogo com esses referencias possibilidades e limites das práticas culturais e sociais que inscrevem corpos e vidas em sistemas de representação.

\section{PROBLEMÁTICAS DOS ESPAÇOS E AS HETEROTOPIAS}


Pensar acerca da relação entre os lugares denominados por interior e por Campo é uma tarefa complexa porque, ao definirmos estes locais, passamos a um processo de problematização sobre a noção do espaço. Podemos acompanhar a dimensão bachelardiana de espaço para compreender que esse termo nos oferece condições para problematizarmos que "[...] a localização nos espaços de nossa intimidade" seria um modo de encontramos as lembranças e, desse modo, de percebermos como as memórias são especializadas (BACHELARD, 1984, p. 203).

Em outra direção, Deleuze e Guattari (1997, p. 54) vão por meio de seus "platôs" desenvolver que o espaço nômade seria localizado, mas não delimitado. Assim, o limite seria do espaço estriado. Com base nas analíticas destes pensadores, podemos compreender que os espaços como lisos e estriados fazem parte de processos de desterritorialização e reterritorialização que são processuais e geram sentidos acerca dos campos e dos modos de se viver que estes locais produzem e são resultados.

O espaço liso ou nômade situa-se entre dois espaços estriados: o da floresta, com suas verticais de gravidade; o da gravidade; o da agricultura, com seu quadriculado e suas paralelas generalizadas, sua arborescência tornada independente, sua arte de extrair a árvore e a madeira da floresta. Mas "entre" significa igualmente que o espaço liso e controlado por esses dois lados que o limitam, que se opõem a seu desenvolvimento e lhe determinam, tanto quanto possível, uma função de comunicação, ou, ao contrário, que ele se volta contra eles, corroendo a floresta por um lado, propagandose sobre as terras cultivadas, por outro, afirmando uma força não comunicante ou de desvio, como uma "cunha” que se introduz (DELEUZE; GUATTARI, 1997, p. 57).

Seguindo ainda por outra direção, Canclini (2008, p. 328) ensina que “[...] todas as culturas são de fronteira [...] Assim, as culturas perdem a relação exclusiva com seu território, mas ganham em comunicação e conhecimento" e, ao mesmo tempo, "[e]m toda fronteira há arames rígidos e arames caídos" (CANCLINI, 2008, p. 349). Desse modo, podemos compreender que os espaços são produzidos e, ao mesmo tempo, produzem sentidos e significados acerca das experiências e das vivências presentes neste território.

Pensar nos espaços só nos faz sentido ao olharmos para as vidas que os constituem, com suas instalações, performances e representações, Nesses elementos, acompanhamos Foucault (2013, p. 19) ao afirmar que "[n]ão se vive em um espaço neutro e branco; não se vive, não se morre, não se ama no retângulo de uma folha de papel”. Assim, a vida seria possível em espaços 
que são constituídos e que se produzem em diferentes condições, “[v]ive-se, morre-se, ama-se em um espaço quadriculado, recortado, matizado, com zonas claras e sombras, diferenças de níveis, degraus de escada, vãos, relevos, regiões duras e outras quebradiças, penetráveis, porosas".

Desse modo, espaços como o interior e o Campo são produzidos nos sistemas de representação como os espaços das cidades conhecidas como Capitais ou metrópoles. Entretanto, diferenças são nítidas como a distribuição de população, o acesso a bens e serviços e os modos que se produzem o habitar, o morar, as relações com a vida não humana e humana em diferentes contextos. Entre tantos elementos, podemos dizer que o espaço é um elemento complexo que é lido no sistema cultural de modos diferentes.

Assim, os modos de experimentar a vida nos grandes centros urbanos, nos espaços do interior e do campo são relacionados aos sistemas de produção de sentidos, as práticas sociais e culturais e, ao mesmo tempo, aos modos como os corpos e as vidas se relacionam em diferentes possibilidades. Entretanto, ao pensarmos nas sexualidades e nos modos de se relacionar com os outros e consigo, os espaços das sexualidades desviantes precisam ser produzidos de diferentes modos nas localidades que aparecem em oposição: Capital/Interior.

Os diferentes modos de compreender espaço como analisam e produzem Bachelard (1984), Deleuze e Guattari (1997) e Canclini (2008) corroboram para pensarmos na confusão das localizações e de suas oposições como a proposta de cisão entre Capital e Interior. "A leveza da zona fronteiriça torna-a muito sensível aos ventos. É uma porta de vai-vem, e como tal nem nunca está escancarada, nem nunca está fechada" (SANTOS, 2001, p. 154-155). A análise do intelectual português nos mostra que a separação é muito sensível e nos provoca a pensar nas diferenças possíveis em caracterizar o interior e o Campo tão complexas como a separação desses espaços geográficos da ideia de Capital.

É nesse sentido que acompanhar Foucault (2013) em suas provocações heterotópicas nos auxilia no processo de discussão da relação entre localidade e sexualidade. O lugar como espaço imaginado, como ambiente de experiências e vivências, como território e como local em que a cultura é produzida e constitui as práticas, as relações e as formas de existir também 
se expressam em encontros diferenciados da dimensão física, mas que permitem o contato com outros modos de ser, de agir e de estar. Assim, as sexualidades dissidentes de forma geral, e especificamente as bichas, geram outras demandas e deslocam o espaço de formas complexas e plurais.

Entendemos que ao pensar em sexualidades, bem como outras experiências corporais e vivenciadas em diferentes contextos, são perpassadas por fluxos informacionais e discursos que prescrevem modos de ser e de agir. Ao pensarmos no acesso midiático aos diferentes discursos, as provocações e as condições de produção de conteúdo, bem como as experimentações de outras formas de sociabilidade pelas redes, precisamos problematizar a distância entre capital e interior como geográfica para abrir brechas sobre os limites tão pouco delineados das experiências culturais e sexuais nestes contextos.

No ciberespaço, surgem novos territórios imateriais assim como novas
territorialidades. Antes da existência do ciberespaço, os territórios e as
territorialidades encontravam-se limitadas às relações sociais (de poder) estabelecidas
nas áreas físicas que ocupavam (territórios-zona). Com o advento de técnicas como o
rádio, TV, telefone, e principalmente internet, ampliando-se os territírios-rede e as
territorialidades decorrentes destes. Portanto, limitar o conceito de território a um
recorte físico/areal não é algo suficiente que permita englobar os diversos territórios
existentes, haja vista que os territórios são cada vez mais descontínuos, fluidos e
imateriais (SAQUET; CANDIOTO; ALVES, 2010, p. 60).

Os atravessamentos dos discursos acerca das experiências de gênero e sexualidades dissidentes não se encontram mais focadas apenas nos espaços físicos que vivemos, mas estão entremeadas às imagens, aos sentidos e aos significados que estão dispersos em diversos suportes comunicacionais contemporâneos. Desse modo, as separações local e global tornamse complexas e, ao mesmo tempo, produzem sentidos acerca dos espaços que ocupamos. As experimentações das estéticas e das políticas que implicam sobre os corpos e as vidas são remodeladas pelos contextos tecnológicos.

Exemplo desse desconforto é a ideia de intimidade e visibilidade que parecem contrárias, mas encontram cada vez mais ecos em uma dimensão em que as redes sociais são alimentadas com fotos e vídeos que narram cotidianos produzidos, sistemas de representação e produzem relações e estereótipos acerca dos modos de se compreender o corpo, a vida e a sexualidade. Preciado (2018, p. 38) analisa o que chama de sexdesign que no processo 
contemporâneo produz relações e modos de se viver, nos quais “[...] o negócio farmacoponográfico é a invenção de um sujeito e, em seguida, sua reprodução global" (PRECIADO, 2018, p. 38).

Assim, compreendemos que os espaços são territorializados em sistemas complexos que compreendem a pluralização de elementos que estão vinculados à dinâmicas econômicas, políticas e culturais. Desse modo, Capital e Interior são engendrados em relações de poder “"[...] produzem os territórios que estão em movimento, de qualquer modo que os territórios são fluidos, podendo ser temporários ou relativamente permanentes" (SAQUET; CANDIOTO; ALVES, 2010, p. 60).

Nesses diferentes espaços, existem as produções de outras formas de sociabilidade e experiências de vida que estão marcadas por discursos e práticas sociais e culturais que geram sentidos acerca dos modos de experimentar as relações sexuais, as formas de prazer e outras possibilidades de ser e de agir no mundo. Desse modo, experimentamos as provocações de Augé (2012) e Canclini (2008) acerca dos fluxos que produzem relações culturais nos espaços e condições de produção de vida nesses lugares.

Ao mesmo tempo em que existem os modos de vivenciar as sexualidades nos espaços da Capital e/ou da metrópole que sugerem uma fluidez de práticas e de experiências de visibilidade, o Interior também é construído por estratégias de relação e realização de modos de ser e de agir no mundo. Os não-lugares de Augé (2012) tratam desses espaços que em diferentes contextos oferecem condições conflitantes da vida e do corpo em lugares que são constituídos e que produzem relações que tornam complexas as delimitações das práticas em diferentes lugares.

[...] entre todos esses lugares que se distinguem uns dos outros, há os que são absolutamente diferentes: lugares que se opõem a todos os outros, destinados, de certo modo, a apagá-los, neutralizá-los ou purificá-los, São como que contraespaços. As crianças conhecem perfeitamente esses contraspaços, é com certeza o celeiro, ou melhor ainda, a tenda de índios erguida no meio do celeiro, ou é então - na quintafeira à tarde - a grande cama dos pais. É nessa grande cama que se descobre o oceano, pois nela se pode nadar entre as cobertas; depois, essa grande cama é também o céu, pois se pode saltar sobre as molas, é a floresta, pois pode-se nela esconder-se; é a noite, pois ali se pode virar fantasma entre os lençóis; é, enfim, o prazer, pois no retorno dos pais se será punido (FOUCAULT, 2013, p. 19-20). 


\section{Revista \\ Debates Insubmissos}

Assim, ao mesmo tempo que estereótipos são produzidos sobre a sociabilidade de vidas e corpos que vivem experiências sexuais dissidentes, uma produção farmacopornográfica capilarmente produz sentidos acerca dos modos como nos relacionamos em diferentes localidades. Com isso, as brechas que podemos produzir acendem desconfortos no processo de gerar outras formas de experimentar nossas relações com os espaços. Foucault (2013) provoca a dimensão da heterotopia como a condição de produção de contraespaços.

Assumimos, de antemão, que as diferenças entre Capital e Interior não alteram a necessidade de produção de contraespaços - heterotopias - das experiências, uma vez que a produção das sexualidades dissidentes é gerada em relações fóbicas que sustentam uma lógica do regime de naturalização da heterossexualidade e da cisgeneridade. A complexa estratégia de cisão entre Interior e Capital participa de uma organização binária que é similar a ideia de fronteiras entre as experiências sexuais e de gênero, como analisa Borrilo (2010, p. 16) ao caracterizar que seria a homofobia uma "guardiã das fronteiras".

Desse modo, problematizar o sistema de produção de sentidos que são efeitos da violência destinada a lésbicas e gays, bem como a toda a comunidade LBGTIA+, inscreve-se na mesma lógica que cinde a dimensão do espaço em Capital - como centro das relações administrativas, políticas e econômicas - dos espaços do interior definidos como lugares menos elaborados nessas condições de sistematização de formas de agir governamentais, políticas e estéticas.

As separações entre sexualidades naturalizadas e dissidentes e as localizações geográficas Capital e Interior precisam do cuidado do questionamento de maneiras que as vivências e experiências não sejam hierarquizadas e organizadas de forma binária entre fáceis e difíceis, entre boas e ruins, entre possíveis e impossíveis. Existem diferenças entre as formas de ser LGBTIA+ nesses espaços, mas as condições que são expressas para a existência das pessoas que dissidentemente vivem suas sexualidades não são favorecidas unicamente por um ou outro polo dessa separação.

Podemos compreender o início do Manifesto Queer Nation que circulou na Parada do Orgulho de Nova York em 1999 ao afirmar que “[n]ão há nada neste planeta que valide, proteja 
ou encoraje a sua existência. É um milagre que você esteja aqui lendo estas palavras. Você deveria, para todos os efeitos, já estar morta” (MANIFESTO QUEER NATION, 2016, p. 2). Reconhecer esse sistema de representação é compreender como somos produzidos por discursos e práticas que nos inscrevem em um sistema que normaliza as práticas heterossexuais em detrimento das sexualidades dissidentes.

O corpo - todos e cada um dos nossos corpos - é o enclave valioso em que transações de poder são incessantemente realizadas. Meu corpo $=$ a multiplicidade e de corpos. Homens e mulheres brancos do pós-guerra são seres biotecnológicos pertencentes ao regime sexopolítico cujo objetivo é a produção, reprodução e expansão colonial da vida humana heterossexual no planeta [...] Somos estranhas ficções biopolíticas porque estamos vivos: somos simultaneamente o efeito do regime de poder farmacopornográfico (biopoder) e o potencial para seu fracasso (bioempoderamento) (PRECIADO, 2018, p. 129).

Incomodados, provocamos a problematização que Capital e Interior são perpassadas por práticas de identificação e processos que localizam corpos e vidas de sexualidades dissidentes e que nos diferentes contextos são necessárias ações de desterritorialização e reterritorialização para aquelas pessoas que não compreendem o padrão heterossexual e cisgênero estruturado por uma lógica farmacopornopolítica que inscreve modos de ser e de agir por meio de discursos que não estão geograficamente definidos nos espaços do Interior e da Capital, mas produzem esses corpos e essas vidas nestes contextos.

Compreendemos, assim, que uma prática espacial ao invés de se localizar na produção de pontas entre Capital e Interior, pode se projetar em espaços fóbicos e normalizados e nas experimentações de lugares que não estão prontos, “[...] espaços absolutamente outros; e, forçosamente, a ciência em questão se chamaria, se chamará, já se chama "heterotopologia" (FOUCAULT, 2013, p. 21). Desse modo, problematizamos que nesses espaços resultados de sistemas culturais, econômicos, políticos e sociais diferentes, existem estratégias e necessidades similares para os corpos e as vidas dissidentes.

Com isso, discutimos experiências espaciais vivenciadas por corpos e subjetividades dissidentes, em especial as bichas, por uma dimensão de criação de lugares outros para a realização dos modos de ser e de estar. Por mais que a ideia inicialmente proposta ao grupo de textos desse dossiê se faça pensando em dimensões de diferenciação entre o espaço dos grandes centros e os interiores e o Campo, a questão que nos move nessa problemática é se há um espaço 
para vivenciar as sexualidades dissidentes, mesmo em lugares entendidos, no senso comum, como aptos para a expressão das sexualidades.

Estimulados pelas proposições de Foucault (2006, 2013) em pensar sobre o espaço e suas variantes que nos levam a localização e, em outra direção, a constituição de dimensões heterotópicas, entendemos que parece existir uma assimetria da compreensão de que em espaços como as grandes cidades a experiência de sexualidades dissidentes seria diferente de um modo que os interiores e o Campo teriam dificuldade em ser.

Primeiro princípio: não há, provavelmente, nenhuma sociedade que não constitua sua heterotopia ou suas heterotopias. Esta é, sem dúvida, uma constante de todo grupo humano. Na verdade, porém, essas heterotopias podem assumir, e assumem sempre, formas extraordinariamente variadas, e talvez não haja, em toda a superfície do globo ou em toda a história do mundo, uma única forma de heterotopia que tenha permanecido constante. Poder-se-ia talvez classificar as sociedades, por exemplo, segundo as heterotopias que elas preferem, segundo as heterotopias que elas constituem (FOUCAULT, 2013, p. 21).

Acompanhando a análise que Foucault (2013) faz acerca das produções de heterotopias como as que se preferem e as que se constituem, intentamos analisar que os espaços das experiências de sexualidades dissidentes, os procedimentos experimentais dos corpos e das vidas de pessoas que não são heterossexuais ocorrem na relação e, ao mesmo tempo, produzem heterotopias para suas realizações.

Em outra direção, problematizamos a ideia de que esses espaços sejam privilegiados, tendo em vista que no interior e no Campo, as experiências dissidentes agem de modos comuns aos espaços entendidos como metropolitanos. A produção de agrupamentos é uma das táticas comuns entre as vidas e os corpos de sexualidades dissidentes que produzem interações de experiência que perfazem outras relações com as práticas culturais e sociais estabelecidas em uma normalização heterossexual. Assim, por mais que existam concepções de produção de atos performativos e, como explicita Butler (2018, p. 6), “[o] gênero, portanto, é uma construção que oculta regularmente a sua própria gênese", criamos outras possibilidades de experimentação desses atos nos espaços em que nos agrupamos.

Entretanto, esses processos de resistência e a criação de oportunidades de se conviver ainda existem interpretações complexas, porque somos produzidos em uma lógica heteronormativa que nos inscreve em uma dimensão simplificadora de corpos e vidas. Assim, 
a sexualidade e os atos performativos de gênero são capturados pelos sistemas de representação tanto nos espaços heterossexuais como nas tentativas heterotópicas de sexualidades dissidentes.

Todo corpo é capaz de produzir excitação sensorial de algum tipo (de linguagem, de imagem, de cheiro, de toque), todo corpo pode chupar ou ser chupado. Todo corpo é ao mesmo tempo tóxico e viciado, "normal" e deficiente, orgânico e tecnologicamente suplementado. Aqui a divisão do trabalho sexual não depende de uma condição natural, mas de uma especialização técnica do corpo, de uma programação somatopolítica (PRECIADO, 2018, p. 317).

A problematização apresentada pelo pensador queer nos indica que existem estratégias de experimentação dos corpos que no processo de produção dos atos performativos que Butler (2018) problematiza nas condições do corpo são compreendidas como possíveis ou impossíveis.

Já a provocação de Foucault (2014, p. 254) move nossa inquietação em pensar sobre as necessidades de compreender um lugar para as vidas e os corpos dissidentes: “Devemos liberar nosso desejo', dizem elas. Não! Devemos criar prazeres novos. Então, talvez, o desejo siga" (FOUCAULT, 2014, p. 254).

Ao pensarmos que os espaços metropolitanos e interioranos, o Campo e a Cidade, o centro e a margem produzem relações diferenciadas das questões de vida de sexualidades desviantes, perguntamo-nos se, de algum modo, fica expresso que espaços compreendidos com locais ou lugares que atentam a um público-alvo que alimenta o sistema econômico e a lógica de mercantilização e monetização de imagens e afetos, bem como o lucro financeiro e social que estes espaços ganham às custas das relações que são normalizadas no sistema heterossexual.

Compreendemos, assim, que ao invés de pensar em uma condição específica do interior e/ou do Campo, a questão que desconforta é a possibilidade dos corpos e vidas de sexualidades dissidentes criarem relações diferenciadas, outras. Foucault (2013, p. 30) diz que o navio "é a heteropia por excelência". Ou temos condições de empreender produções para navegar de outros modos nas experiências corporais e subjetivas acerca das sexualidades, ou os padrões heteronormativos nos condicionam a reproduzir e fazer a manutenção de atos performativos heterossexuais de tal modo que não escapamos e nem produzimos em outras direções que nos levem a questionar as biotecnologias e os sistemas farmacopornopolíticos que inscrevem nossas relações afetivas, sexuais e corporais em imagens de consumo. 


\section{MÉTODOS E OUTRAS POSIÇÕES}

No intuito de acompanhar a discussão teórica e as inscrições que localizam a noção de espaço e as provocações inscritas neste texto, bem como alinhavar as relações teóricas apresentadas inicialmente, as escolhas metodológicas deste estudo estão inscritas no objetivo de explicitar os modos e as perspectivas deste estudo. Assim, este texto é resultado de um estudo qualitativo, exploratório, bibliográfico e documental e, com base nos referenciais teóricos dos estudos culturais e das teorizações queer problematiza-se a noção de espaço e discute-se as relações de Capital e Interior como espaços para corpos e vidas de sexualidades dissidentes da norma heterossexual.

Acompanhando as descrições dos métodos por Gil (2002) e Severino (2008), compreendemos que um estudo qualitativo empreende o levantamento de ideias e sentidos acerca de um fenômeno de modo a explicitar as condições e os processos que constituem um fenômeno. Assim, o estudo é exploratório porque inicia um levantamento que é necessário sobre as práticas de corpos e subjetividades dissidentes da heterossexualidade para problematizar outros modos de viver as relações com o prazer e as expressões de suas sexualidades.

Este estudo embasa-se nos métodos bibliográfico e documental porque utilizamos as contribuições de autoras e autores para problematizar a dinâmica acerca dos conceitos como espaço, gênero e sexualidade e por meio desta empreendemos uma analítica a partir do vídeo intitulado "Gay do interior X gay da capital: beijo, namoro, aplicativo..." do youtuber Klébio Damas postado em seu canal no YouTube "Mundo Paralelo", no qual discute diferenças entre experiências gays da capital e do interior, destacando "pontos negativos e pontos positivos" desses lugares (MUNDO PARALELO, 2020, s/p.).

O vídeo foi publicado no dia 26 de abril de 2020 e o produtor de conteúdo é assumidamente bissexual e trata de diferentes assuntos que envolvem o cotidiano, as experiências e as relações com a Comunidade LGBTIA+, entre outros temas como relacionamentos, curiosidades e representações. 


\section{INTERIOR E/OU CAPITAL: EXISTE LUGAR PARA AS BICHAS?}

Existe lugar para as bichas? Instigados por esta inquietação exploramos o vídeo de Klébio Damas como uma fonte de experiências, uma vez que ele nos apresenta narrativas acerca das diferenças entre as experiências de gays no interior e na capital, tendo em vista suas vivências na cidade de Itaperuna/RJ e os quatro anos vivendo na capital paulistana. Ao longo do vídeo ele destaca algumas dimensões para traçar comparações, tais como: jeito de ser; machos disponíveis; pegação; aceitação e preconceito.

Ao traçar características a respeito do jeito de ser gay no interior, ele expande os exemplos para outras vivências não heterossexuais, e comenta que a maioria das pessoas vivem sua sexualidade no armário, ou seja, sem que suas vivências sejam públicas ou conhecidas pelas demais pessoas, comentando ainda que: "Morei 18 anos e conheci só um gay que era o cabelereiro da cidade "[...] hoje em dia quando volto para lá, aparece, parece que sai do bueiro. Também sou, também sou, também sou. Mas, ninguém sabe" (MUNDO PARALELO, 2020, s/p). Ao afirmar isso, Klébio registra que a dimensão da experiência no interior está vinculada a um grupo de representações acerca das sexualidades dissidentes

Podemos destacar, inicialmente, que as experiências dissidentes nos ensinam sobre a malha das relações de poder que inscrevem nossos modos de ser e de agir e que acionam complexidades na ideia de visibilidade para as práticas dissidentes de gênero e sexualidade.

\footnotetext{
O armário não é uma característica apenas das vidas de pessoas gays. Mas, para muitas delas, ainda é a característica fundamental da vida social, e há poucas pessoas gays, por mais corajosas e sinceras que estejam de hábito, por mais afortunadas pelo apoio de suas comunidades imediatas, em cujas vidas o armário não seja ainda uma presença formada (SEDGWICK, 2007, p. 22).
}

Retomamos a contribuição de Sedgwick (2007) para problematizarmos não apenas o mostrar/esconder que significa a epistemologia do armário, mas a complexidade de ser visível/invisível as redes de poder que inscrevem os modos como vivenciamos nossas expressões sexuais como corpos e vidas dissidentes das normas.

Diante disso, pensar com as dimensões heterotópicas nos parece produtivo, pois tornase um modo de indicar " [...] uma espécie de contestação simultaneamente mítica e real do 
espaço em que vivemos" (FOUCAULT, 2006, p. 416). E no contexto desta análise, pensar sobre as relações com os lugares é também compreender como a lógica heterossexual se organiza.

A apropriação do espaço público é o sinal da desigualdade cotidiana em função da qual os homossexuais não podem manifestar abertamente sua afeição, e - quando chegam a superar esse olhar reprovador - eles não podem deixar de pensar que, no fundo, sua atitude é provocadora, militante e exibicionista (BORRILO, 2010, p. 113).

A explicitação do autor das dificuldades de visibilidade e de experiências de homossexuais, também marca que os espaços públicos em diferentes contextos nos colocam em risco. A visibilidade é complexa porque seja no interior ou na capital, existem padrões fóbicos que orientam e sustentam essa lógica.

Entretanto, o youtuber vai assumir que na capital "as pessoas são mais leves, livres, mais soltas” e, logo em seguida diz: "[...] no interior também tem. Têm as afeminadas. No interior tem que ter muita bala na agulha para bater de frente. Inclusive é muito importante. Se você é uma dessas pessoas, parabéns. São realmente essas pessoas que movem a causa, que botam a causa pra frente" (sic.) (MUNDO PARALELO, 2020, s/p.). Com essa percepção de Klébio, destacamos que mostrar afeto em público pode não parecer um risco e, ao mesmo tempo, é uma ação política de mostrar-se possível. Entretanto, a partir do momento que expressamos nossas dissidências, o poder nos toma por alvo. Somos passíveis do ataque.

Evoca-se a figura da bicha - afeminada, delicada, sensível, esperta, exótica e problematizadora do binário de gênero - para incomodar as condições das experiências no Interior e na Capital que oportunizam discussões acerca dos modos de vivenciar as sexualidades dissidentes. Nessas duas localizações geográficas existem pessoas que utilizam a norma para se proteger e também para se privilegiar dos lugares de poder que a masculinidade e a feminilidade naturalizadas são bem aceitas e acolhidas, como também existem aqueles/as que causam fissuras nos modos de existir, de amar e de ser.

Desse modo, percebemos que mesmo ao tentar separar as experiências de sexualidades dissidentes no interior e na capital, existem elementos que dificultam essa dimensão porque a experiência performativa é produzida de diferentes modos. Ao sair à rua, mesmo que o corpo esteja engendrado em diferentes contextos nos atos performativos, este corpo e esta vida estão sob avaliação nos dois espaços. Conflitamos com as normas de gênero e as 
heteronormatividades em diferentes graus, entretanto, a lógica que temos no senso comum é que os chamadas cidades grandes - capitais e metrópoles - seriam menos complexas essas visibilidades.

Com isso, enfatizamos que mesmo que um corpo dissidente das normas heterossexuais esteja em uma capital, este também será atravessado pelos sistemas de opressão e pelos processos sociais que indicam as compreensões de como a vidas dissidentes são dissonantes da dimensão generificada que imprime força nas cisões entre masculinidade e feminilidade e, que inscreve a lógica heteronormativa em diferentes contextos. De tal modo isso ocorre, que a cultura pressupõe que um corpo em atos performativos masculinos e/ou femininos que esteja inserida nos padrões culturais seja aceito ou não pelos sistemas de normas.

Assim, compreendemos a afirmação de $\operatorname{Butler}(2018$, p. 9) em que a pensadora enfatiza que "[...] uma das maneiras de reproduzir e ocultar esse sistema de heterossexualidade compulsória é cultivar os corpos em sexos distintos, dotados de aparências 'naturais' e disposições heterossexuais "naturais"” (BUTLER, 2018, p. 9). Acompanhamos a análise, problematizando que o sistema heteronormativo estrutura modos de ser e de agir que localizam, sejam nas capitais ou nos interiores, modos de ser e de agir que são marcados pelos sistemas de representação.

Klébio continua expressando as narrativas que compreende serem diferentes das experiências de gays no interior e na capital e fala sobre o julgamento das pessoas com as roupas usadas, a marcação familiar que é expressa em saber quem são os pais de um ou outro corpo. Essas referências são diluídas para o youtuber no espaço da capital. Ele afirma que são possíveis outras formas de ser e que a cidade grande oferece outras condições. Nesse momento, o produtor de conteúdo apresenta as tribos que são agrupamentos por elementos estéticos e/ou culturais de homens gays: ursos, padrões, alternativos, entre outros.

É relevante marcar que esses agrupamentos que são codificados por elementos estéticos, práticas culturais ou posicionamentos e representações continuam sendo localizações como: saber quem são os pais, qual bairro moramos ou ainda as roupas que vestimos. Assim, na tentativa de mostrar uma pluralidade, Klébio marca que os padrões de localização dos corpos e 
das vidas dissidentes na capital e no interior são diferentes, mas compostos de uma lógica de organização e de localização dos corpos e das subjetividades em diferentes contextos.

Nessa direção, pensar sobre os modos como os corpos e as vidas dissidentes se organizam e se relacionam é também compreender como a localização, o sistema de significação e os grupos de representação sobre as sexualidades dissidentes estruturam modos de agir e de pensar. Desse modo, mesmo que mudem os referenciais que indiquem os corpos e as vidas dissidentes, isso não significa que essas subjetividades sejam livres e/ou que o sistema fóbico não constitua as relações entre esses corpos e a norma heterossexual.

Ao tratar sobre as possibilidades de relações afetivas e sexuais nos espaços do interior e da capital, o youtuber discute que tanto no interior como na capital está vinculada a ideia de grupos e espaços de encontros comuns. A diferença entre interior e capital para Klébio é que no interior o grupo de pessoas que são possíveis para o envolvimento é reduzido no interior porque as pessoas que se relacionam no interior fazem parte dos mesmos círculos sociais. A capital também é organizada nos bairros e regiões e cria nichos e grupos de relação. Assim, por mais que os espaços sejam plurais na capital, a organização das comunidades de corpos e vidas dissidentes são localizadas e fechadas em determinados grupos.

"A gente precisa diferenciar um interior de 5 mil habitantes, para um interior de 1 milhão de habitantes, sabe? [...] E, também, tem interiores com 30 mil habitantes que aceitam mais e tem interiores que tem 30 mil habitantes que aceitam menos." (MUNDO PARALELO, 2020, s/p.). Ao trazer essa ideia de localização sobre os espaços e os modos como se aceitam as dissidências sexuais de corpos e vidas, é relevante marcarmos que, ao mesmo tempo que tentamos localizar espaços fóbicos e lugares que possam ser confortáveis, isso não é possível de se definir pela lógica Capital e Interior.

Existem marcas sociais, culturais, políticas, éticas e estéticas que atravessam corpos e vidas e que localizam quem a norma invisibiliza e quem é atingido pelos sistemas de opressão que destituem esses corpos e vidas de direitos e de possibilidades de existência. Assim, perpassados por marcadores de gênero, de sexualidade, de raça, de etnia, de geração, de 
localização geográfica, de classe, as vidas e os corpos são definidos como possíveis e descartáveis nos sistemas culturais e nas práticas políticas das sociedades em que vivemos.

Ao tratar sobre os encontros sexuais e afetivos, o youtuber diz que no interior é mais difícil ficar com corpos e vidas dissidentes e que não pode ocorrer um encontro "em qualquer lugar, se não você pode virar fofoca da cidade" (MUNDO PARALELO, 2020, s/p.). Na Capital ele afirma que "tudo é mais de boa, tudo é mais leve".

Ao acompanharmos a análise das vidas dos homens infames, em que Foucault (2003, p. 220) analisa registros do Hospital Geral e do Hospital da Bastilha para tratar sobre os escritos que marcam o lugar da loucura nos corpos e nas vidas daquele momento, o intelectual problematiza como a visibilidade que está inscrita nos modos de registro estão também fabricando modos de se experimentar a realidade e constituí-la. Assim, o filósofo nos explica que não seria complexo e denso e, desse modo de uma necessidade de aprender técnicas de desarmamento das inscrições e lógicas do poder se ele apenas "vigiar, espreitar, surpreender, interditar punir", entretanto, é da complexidade dispositiva do poder a produção, ou seja, "ele incita, suscita, produz, ele não é simplesmente orelha e olho; ele faz agir e falar" (FOUCAULT, 2003, 220).

E quem pode agir e falar? A quem o poder inscreve como possível, pensar a norma que estabelece a lógica constitutiva da maquinaria heterossexual é compreender que os mais próximos - ou ainda, os que melhor replicam os modelos da heterossexualidade - estão em condições diferentes das subjetividades, das vidas e dos corpos em desvio. Ser visível é arriscado e, ao mesmo tempo, quem assume o risco, está também produzindo uma dimensão do poder, uma lógica produtiva. As bichas sempre tiveram esse papel transgressor aos modelos heteronormativos, criando resistência com sua existência e apresentando modelos outros, heterotopias para vivenciar o gênero e a sexualidade. Ao comentar da figura do cabelereiro da cidade em que nasceu, Klébio diz que ela representava a homossexualidade para ele nas experiências do interior. Mesmo que essa representação não servisse como um modelo pronto para ele, não gerando um processo de identificação, ela abria caminhos para a existência de outras transgressões, evidenciando que o sistema heteronormativo não era o único possível. 


\section{Revista \\ Debates Insubmissos}

Vale destacar também, que o advento da internet e a criação de cyberespaços proporcionou a expansão de muitos modos de ser bicha, tornando essa figura mais plural, trazendo para o interior a possibilidade de uma figuração mais coletiva e menos individual da bicha.

No intuito a resistir, Preciado (2019, p. 417) por meio de suas táticas contrassexuais nos ensina que uma das formas de atuar nessas estratégias de análise e crítica é "operar como a exceção perversa que confirma a regra da natureza", isso é possível porque "[...] a falha é constitutiva da máquina heterossexual". Ao mesmo tempo que nos aproximamos dessa compreensão, é relevante compreender que o poder atua na construção dessas experiências dissidentes e produz, assim, uma lógica narrativa de exemplo dos corretos e dos incorretos.

\footnotetext{
Mesmo porque a heterossexualidade é uma tecnologia social e não uma origem natural fundadora. É possível inverter e derivar (modificar o curso, mudar, submeter à deriva) suas práticas de produção da identidade sexual. A bicha, o travesti, a drag queen, a lésbica, a sapa, a caminhoneira, a butch, a machona, a bofinho, as trangêneras, as F2M e os M2F são "brincadeiras ontológicas", imposturas orgânicas, mutações prostéticas, recitações subversivas de um código sexual transcendental falso (PRECIADO, 2019, p. 417).
}

Problematizar a complementaridade norma/desvio é uma das formas de discutir também a relação entre correto/incorreto, bom/mau, Capital/Interior. Esses binários que se localizam na dimensão da fala do youtuber, mas também na lógica que estabelecemos sobre as experiências dissidentes em diferentes lugares possibilita compreendermos que o sistema das relações de poder produz uma lógica de contraposição e complementaridade da norma e do desvio e, desse modo, quanto menor a visibilidade - característica que a Capital oferece - o desvio deixa de ser individual e passa a ser compreendido como geracional, geográfico ou cultural.

Entretanto, o sistema das opressões expressas da fobia dos corpos e das vidas dissidentes ocorre em todos os espaços porque a heterossexualidade, por meio do discurso de naturalização religioso, científico e artístico nos localiza como a exceção que está disponível para ser vista como exótica, moderna ou inovadora. Características que combinam com o espaço dos grandes centros metropolitanos e que destoam do sentido de arcaico, provinciano e rude dos espaços do Interior.

[...] nossas imagens sobre a homossexualidade foram construídas. Para além dessa moldura, existem outros elementos de explicação que, eventualmente, nos permitem 
circunscrever melhor a hostilidade contra os gays e as lésbicas. Ao preconizar a divisão dos sexos e ao radicalizar a diversidade dos gêneros, a ideologia diferencialista transforma a repulsa (ou a segregação) relativamente a homossexuais em um elemento central capaz, ainda por cima, de garantir o equilíbrio individual e a coesão social (BORRILO, 2010, p. 88).

Sobre o preconceito, ele explica que "como as coisas precisam ser escondidas, as coisas LGBTs acabam sendo muito underground, muito escondidas e acaba sendo muito perigoso" (MUNDO PARALELO, 2020, s/p.).

Ao mesmo tempo que podemos pensar que existem espaços que as cidades entendidas como grandes destinam a população LGBTIA+, bem como eventos, bares, casas noturnas e, até mesmo, zonas e ruas que são compreendidas como mais abertas ou até mesmo liberais para a experiência dissidente de produção e publicização de afetos, em outra direção, os interiores e o Campo também produzem espaços experimentais que entendemos serem, em uma dimensão afetiva, corporal e de vida, expressões heterotópicas.

Ao finalizar as diferenças sobre Capital e Interior, o youtuber afirma que "Na capital [o preconceito] é levemente menor, mas não é muito menor" (MUNDO PARALELO, 2020, s/p.). Desse modo, a narrativa de diferença entre esses espaços que são compreendidas como localização, poderiam ser entendidas como complexas relações de inscrição do poder que nos captura, organiza, seleciona, impele, produz e define espaços e condições possíveis.

Se é da ordem da localização, diferenciamos que o interior é o espaço em que o corpo e a vida dissidente é localizada no sujeito, no indivíduo, na pessoa. Nos espaços da Capital, a localização se dá como uma característica do espaço urbano e volátil dos grandes centros como uma dimensão de grupo, de população, de geração. Assim, mesmo que possamos ver casais LGBTIA+ em diferentes espaços de São Paulo, como apresenta Klébio e, assim, também vemos expressões de afeto e de sexualidade nesses espaços, essas pessoas participam de uma dimensão comunidade diferente das pessoas do interior.

As localizações possíveis na malha do poder nos mostram os sistemas de governamento que se inscrevem sobre a lógica da normalidade e da anormalidade. Foucault (2003) ao tratar sobre as capturas narrativas da definição de loucura que estavam marcadas nos relatos dos 
Hospitais, nos mostra que o poder produz modos de comportar-se, de organizar-se e de ser possível.

Assim, ao tomarmos a questão que intitula esse texto: "tem lugar para as bichas"? Dizemos que não, este lugar pronto, definido e certo não existe, ele é produzido.

\begin{abstract}
Observemos que ainda no século XIX havia colégios para os rapazes, havia também o serviço militar que, sem dúvida, desempenhavam esse papel: era preciso que as primeiras manifestações da sexualidade viril ocorressem em outro lugar. E, para as jovens, pergunto-me se, afinal, a viagem de núpcias não constituía, ao mesmo tempo, uma espécie de heterotopia e de heterocronia: era preciso que a defloração da jovem não ocorresse na mesma casa onde ela nascera, era preciso que esta defloração ocorresse, de certo modo, em parte alguma (FOUCAULT, 2013, p. 21-22).
\end{abstract}

Ao vermos a análise que o pensador faz das experiências heterossexuais e das necessidades que as práticas exigem de criação de espaços, nós, que somos lidos e compreendidos em nossa dimensão - ou acompanhando a análise de Butler (2018) - produzidos pelos atos performativos de gênero como não coerentes com o sistema de normalização, estamos em processos produtivos que deslocam as dimensões dos corpos e das vidas dissidentes nas construções - mesmo que provisórias, que fragmentadas e possíveis - de espaços heterotópicos para as realizações de nossos modos de vida.

Por mais que existam espaços constituídos em diferentes cidades metropolitanas, bem como em municípios do interior que são declaradamente abertas às pessoas LGBTIA+, estes são lugares incômodos para o sistema social de modos complexos. Assim, em diferentes regiões, destacam-se as oportunidades de viver que parecem possíveis nos grandes centros, entretanto, estes são espaços de resistências criados pelas próprias comunidades, grupos, pessoas para experimentarem seus corpos e suas vidas dissidentes.

Coagidos e produzidos, no Interior ou na Capital, o poder não deixa de nos localizar individual e coletivamente, de engessar nossos modos de nos comportar e de gerar possibilidades no sistema heterossexual. Assim, sermos vistos nos coloca também em outra problemática que é a condição de resistência que a norma inscreve no desvio. Ao assumirmos as posições de confronto, de desconforto e desarticulação da naturalização da heterossexualidade, existe um jogo discursivo que nos produz como o desvio a ser evitado. 


\section{Revista \\ Debates Insubmissos}

Desse modo, a experiência espacial heterotópica são maneiras de corpos e vidas dissidentes abrirem brechas nos atos performativos naturalizados, criar outras formas de experimentação de outra vida e corpo e das que estamos ensinados. Assim, há provocações necessárias a dimensão de que exista um lugar para as bichas, mesmo que nos grandes centros e/ou em espaços que são territorializados como para a comunidade LGBTIA+, tendo em vista que existem códigos corporificados e normalizados para produzir uma dimensão de homossexualidade normalizada pela dimensão heterossexual.

A experiência heterotópica dos espaços do interior e da capital para as vivências das bichas mantêm o gosto da diáspora caracterizada por Hall (2003). As experiências que produzimos e que nos deparamos continuamente nos constituem a sensação de distância e proximidade provisórias com a Capital e o Interior como se tivéssemos deixado nosso lugar de origem e nunca chegado ao nosso destino como narra o pensador. Assim, a diáspora também se torna uma sensação e uma experimentação dessas vidas e subjetividades que como as bichas não encontram espaços para si e produzem outros para viver.

Localizar, antes, deveria ser uma ação tática para pensar como as sexualidades dissidentes que expressam corpos e vidas outras podem existir e os riscos e benefícios de nossas táticas de desarmamento da heterossexualidade naturalizada.

\section{CONSIDERAÇÕES FINAIS}

Este texto tem como provocação a discussão sobre a lógica Capital e Interior para problematizar as experiências de corpos e vidas dissidentes das normas sexuais e de gênero. Desse modo, a questão que orienta essa pesquisa foi: as experiências de corpos e vidas dissidentes das normas de gênero e sexualidade nas lógicas produtivas e coercitivas do poder que naturaliza a heterossexualidade são inscritas de modos diferentes nas localizações Interior e Capital? Incomodados por esta questão, o objetivo geral deste estudo é problematizar as relações entre espaço, sexualidades e dissidências das normas de gênero e sexualidade.

Compreendemos, assim, que a questão orientadora pode ser respondida, inicialmente, que existem disparidades e diferenças das vivências e das experiências nos lugares da Capital 
e do Interior, entretanto, as experiências fóbicas que localizam, inscrevem, produzem e coagem as experiências de corpos e vidas dissidentes agem de forma a localizar em pessoas e em grupos nos espaços discutidos.

Pensar sobre esses espaços e sobre as vidas e os corpos dissidentes são modos de problematizar também as condições de experiência e de vivência sobre o corpo não heterossexual. Assim, o intuito dessa discussão é problematizar como as condições de experiências e vivências em que as sexualidades desviantes de corpos e vidas dissidentes não são menos ou mais seguras ou mesmo confortáveis.

O poder nos atravessa de diversos modos. Produz a naturalização da heterossexualidade e nos registra no sistema de inscrição dos saberes acerca da sexualidade os desvios, ora produtivos e potentes, ora limitados e coagidos. A norma heterossexual é uma naturalização que no Interior e na Capital continua por meio dos sistemas fóbicos a desestabilizar, ferir física, verbal, psicológica, afetiva, emocional, econômica, ética e estética as vidas e os corpos que não compactuam com os sistemas de opressão.

A contribuição deste estudo para o campo, no intuito da continuidade das pesquisas foi problematizar sobre as táticas e estratégias que nos permitam, de algum modo, a desarmar a heterossexualidade naturalizada e provocar condições produtivas em espaços diferentes. Desse modo, as diferenças no centro e na margem da ideia de capital e interior ainda não é díspar a ponto de afirmar que o espaço da metrópole é seguro. Estamos em risco. Somos resultado de uma ação de resistência. O poder age em nossa direção. Nos aflige.

Assumir que não há um lugar na Capital e no Interior para a bicha não faz com que ela seja impossível, mas desterritorializada, heterotópica por excelência. Os espaços em que a bicha chega, mexe, produz, incomoda e constitui - mesmo que provisoriamente - são espaços em que a estabilidade da naturalização do binário de gênero e do conforto da norma heterossexual são questionados por aqueles/as que vivem no conforto e na proteção dessas dimensões de poder. Assim, a Capital ou o Interior não são seguros ou acolhedores de forma natural. A bicha carrega a diáspora como quem coloca uma música para tocar em ambientes inapropriados. Seu rebolado 
em qualquer lugar é desconfortável para quem não aprendeu a dançar sua música e fíca repetindo os passos com medo de fazer feio. A bicha a bonita pra caramba.

\section{REFERÊNCIAS}

AUGÉ, Marc. Não lugares: introdução a uma antropologia da supermodernidade. Trad. Maria Lúcia Pereira. 9. Ed. Campinas/SP: Papirus, 2012.

BACHELARD. A poética do Espaço. In: Os pensadores. 2. ed. São Paulo: Abril Cultural, 1984. (181-354).

BORRILO, Daniel. Homofobia: história e crítica de um preconceito. Trad. Guilherme João de Freitas Teixeira. Belo Horizonte: Autêntica, 2010.

CANCLINI, Néstor García. Culturas Híbridas, Poderes Oblíquos. In: CANCLINI, Néstor García. Culturas Híbridas: estratégias para entrar e sair da modernidade. 4.ed. São Paulo: Editora da Universidade de São Paulo, 2008. (283-350).

DELEUZE, Gilles; GUATTARI, Félix. Tratado de Nomadologia: a máquina de guerra. In: DELEUZE, Gilles; GUATTARI, Félix. Mil Platôs - capitalismo e esquisofrenia. Vol. 5. São Paulo: Ed. 34, 1997.

ESCOSTEGUY, Ana Carolina D. Cartografias dos estudos culturais - Uma versão latinoamericana - ed. on-line - Belo Horizonte: Autêntica, 2010.

FOUCAULT, Michel. A vida dos homens infames. In: FOUCAULT, Michel. Estratégia, poder-saber. Ditos e Escritos IV. Rio de Janeiro. Forense Universitária, 2003. (203-222).

FOUCAULT, Michel. Outros Espaços. In: Motta, M. B. (Org). Michel Foucault Estética: Literatura e pintura, música e cinema. tradução Inês Autran Dourado Barbosa. 2. ed. Rio de Janeiro: Forense Universitária, 2006. (Ditos \& Escritos. v. III), (411-422).

FOUCAULT, Michel. As Heterotopias. In: FOUCAULT, Michel. O corpo utópico; as heterotopias. Trad. Salma Tannus Muchail. São Paulo: n-1 edições, 2013. (19-32).

FOUCAULT, Michel. Ditos e Escritos IX: genealogia da ética, subjetividade e sexualidade. trad. Abner Chiquieri. Rio de Janeiro: Forense Universitária, 2014.

GIL, Antônio Carlos. Como elaborar projetos de Pesquisa. 4.ed. Atlas: São Paulo, 2002.

HALL, Stuart. Da Diáspora: Identidades e mediações culturais. Belo Horizonte/MG: Editora UFMG, 2003.

HARAWAY, Donna. Saberes localizados: a questão da ciência para o feminismo e o privilégio da perspectiva parcial. Cadernos Pagu, Campinas, 1995. (7-41). 
MISKOLCI, Richard. Teoria Queer: um aprendizado pelas diferenças. 2. ed. Belo Horizonte: Autêntica Editora; UFOP - Universidade Federal de Ouro Preto, 2012.

MUNDO PARALELO. Gay do interior X gay da capital: beijo, namoro, aplicativo... Klébio Damas. YouTube. Disponível em: https://www.youtube.com/watch?v=9d85fVMuQjE. Acesso: 29 abr. 2020.

NELSON, Cary; TREICHLER, Paula A.; GROSSBERG, Lawrence. Estudos Culturais: uma introdução. In: SILVA, Tomaz Tadeu da (org.). Alienígenas na sala de aula. 7.ed. Petrópolis/RJ: Vozes, 2008. (7-20).

PRECIADO, Paul B. O que é contrassexualidade? In: HOLLANDA, Heloisa Buarque de. (Org.). Pensamento Feminista: conceitos fundamentais. Rio de Janeiro: Bazar do Tempo, 2019. (411-420).

RAFFESTIN, Claude. Uma concepção de território, territorialidade e paisagem. In: PEREIRA, Silvia Regina; COSTA, Benhur Pinós; SOUZA, Edson Belo Clemente de (orgs.). Teorias e práticas territoriais: análises espaços-temporais. 1.ed. São Paulo: Expressão Popular, 2010. (13-24).

SANTOS, Boaventura de Sousa. Modernidade, Identidade e a Cultura de Fronteira. SANTOS, Boaventura de Sousa. Pela mão de Alice: o social e o político na pósmodernidade. 8.ed. São Paulo: Cortez, 2001.

SAQUET, Marcos Aurélio; CANDIOTTO, Luciano Zanetti Pessôa; ALVES, Adilson Francelino. Construindo uma concepção reticular e histórica para estudos territoriais. In: PEREIRA, Silvia Regina; COSTA, Benhur Pinós; SOUZA, Edson Belo Clemente de (orgs.). Teorias e práticas territoriais: análises espaços-temporais. 1.ed. São Paulo: Expressão Popular, 2010. (53-68).

SEDGWICK, Eve Kosofsky. A epistemologia do armário. Cadernos Pagu. v. 28. n. 19 Campinas, 2007 (19-54).

SEVERINO, Antônio Joaquim. Metodologia do trabalho científico. 23 ed. 7 reimp. São Paulo: Cortez, 2008.

TAKARA, Samilo. Uma pedagogia bicha: homofobia, jornalismo e educação. Programa de Pós-Graduação em Educação. UEM/PR, 2017

TERUYA, Teresa Kazuko. Sobre Mídia, Educação e Estudos Culturais. In: MACIEL, Lizete Shizue Bomura; MORI, Nerli Nonato Ribeiro (orgs). Pesquisa em Educação: múltiplos olhares. Maringá: Eduem, 2009. (151-165).

Submetido em: 28/06/2020

Aprovado em: 16/07/2020 